\title{
Thermodynamic Analysis of Biomass Gasification by Different Agents
}

\author{
Cesare Freda*, Ulisse Della Vittoria, Emanuele Fanelli, Giacinto Cornacchia, Giacobbe Braccio
}

ENEA, Laboratory of Thermochemical Processes for Wastes and Biomass Valorization, SS Jonica 106 km $419+500,75026$

Rotondella, MT, Italy

Corresponding Author Email: cesare.freda@enea.it

https://doi.org/10.18280/ti-ijes.642-401

Received: 25 February 2020

Accepted: 3 June 2020

\section{Keywords: \\ biomass, char, equivalence ratio, gasification, simulation, syngas}

\begin{abstract}
Biomass gasification was investigated by a thermodynamic analysis with the scope to understand the effect of the injection of different gasifying agents and of the gasification temperature on the output variables of process. The thermodynamic analysis was carried out by a freeware commercial software. Gasification temperature in the range of $750-950^{\circ} \mathrm{C}$, together with different gasification agents air and steam, were investigated. In the case of air process equivalence was varied up to complete combustion of the biomass. For steam gasification the molar steam/biomass ratio was increased up to 9 . The investigated output variables of the process were gas yield, heating value and gas composition.
\end{abstract}

\section{INTRODUCTION}

Biomass is the organic material produced by chlorophyll photosynthesis during which plants absorb the sun's energy to convert carbon dioxide and water into carbohydrates. Biomass can be considered as a chemical storage of energy from the sun. Biomass can be converted by gasification into a valuable product, the so-called "syngas", that is a mixture of carbon monoxide, hydrogen, carbon dioxide, methane and light hydrocarbons, nitrogen. The by-product of gasification is the char, a carbon-based material that contains the metallic elements of the starting feedstock. During gasification, biomass is partially oxidized at temperature of $700-900{ }^{\circ} \mathrm{C}$ by injecting a gasifying-oxidant agent such as air, oxygen, steam or carbon dioxide. Historically, syngas from gasification was used for cooking, lighting and to fuel automotive engine. More recently, biomass gasification has been arousing scientific interest because of its renewable nature that can contribute to approach the "Climate Neutrality by 2050 ", announced by the European Commission with the Green Deal. In fact, syngas can used for heat and power production, can be converted into fuels such as diesel, gasoline, methanol and dimethyl ether (DME), ethanol, and other green chemicals.

Under gasification, the solid feedstock is dried, and then it is pyrolyzed. The pyrolysis could be described by the following reaction:

\section{$\mathrm{C}_{\alpha} \mathrm{H}_{\beta} \mathrm{O}_{\gamma} \rightarrow \mathrm{aCO}+\mathrm{bH}_{2}+\mathrm{cCH}+\mathrm{dCO}_{2}+\mathrm{eH}_{2} \mathrm{O}+\mathrm{fC}+\mathrm{gC}_{\delta} \mathrm{H}_{\varepsilon} \mathrm{O}_{\vartheta}$}

It starts at about $250-300{ }^{\circ} \mathrm{C}$, and converts the biomass, $\mathrm{C}_{\alpha} \mathrm{H}_{\beta} \mathrm{O}_{\gamma}$, into gas, volatile compounds $\left(\mathrm{C}_{\delta} \mathrm{H}_{\varepsilon} \mathrm{O}_{\vartheta}\right)$, and char. The heat of biomass pyrolysis is influenced by various factors, anyway it is generally accepted that it is an endothermic step [1]. After pyrolysis, the gas and volatiles can then react in secondary reactions with each other and with the char to form gas. The main reactions of the gasification step are reactions are the following heterogeneous ones:
$\mathrm{C}+\mathrm{CO}_{2}=2 \mathrm{CO} \quad \mathrm{H}^{\circ}(298 \mathrm{~K})=+172.6 \mathrm{KJ} / \mathrm{mol} \quad$ Boudouard $\mathrm{C}+\mathrm{H}_{2} \mathrm{O}=\mathrm{CO}+\mathrm{H}_{2} \mathrm{H}^{\circ}(298 \mathrm{~K})=+131.3 \mathrm{KJ} / \mathrm{mol} \quad$ Char steam reforming $\mathrm{C}+2 \mathrm{H}_{2}=\mathrm{CH}_{4} \quad \mathrm{H}^{\circ}(298 \mathrm{~K})=-74.87 \mathrm{KJ} / \mathrm{mol} \quad$ Methanation

While non less important are the following gas phase reactions for the composition of the syngas:

Methane steam reforming

$$
\begin{gathered}
\mathrm{CH}_{4}+\mathrm{H}_{2} \mathrm{O}=3 \mathrm{H}_{2}+\mathrm{COH}^{\circ}(298 \mathrm{~K})=+206.1 \mathrm{KJ} / \mathrm{mol} \text { Water gas shift } \\
\text { reaction } \\
\mathrm{CO}+\mathrm{H}_{2} \mathrm{O}=\mathrm{CO}_{2}+\mathrm{H}_{2} \mathrm{H}^{\circ}(298 \mathrm{~K})=-41.23 \mathrm{KJ} / \mathrm{mol}
\end{gathered}
$$

Globally, the drying, pyrolysis and gasification step are endothermic, thence heat supply is necessary to sustain the process. Usually it is provided by partial combustion of the combustible molecules that can be described by the exothermic reactions:

$$
\begin{array}{cl}
\mathrm{C}+1 / 2 \mathrm{O}_{2} \rightarrow \mathrm{CO} & \mathrm{H}^{\circ}(298 \mathrm{~K})=-111 \mathrm{KJ} / \mathrm{mol} \\
\mathrm{CO}+1 / 2 \mathrm{O}_{2} \rightarrow \mathrm{CO}_{2} & \mathrm{H}^{\circ}(298 \mathrm{~K})=-283 \mathrm{KJ} / \mathrm{mol} \\
\mathrm{H}_{2}+1 / 2 \mathrm{O}_{2} \rightarrow \mathrm{H}_{2} \mathrm{O} & \mathrm{H}^{\circ}(298 \mathrm{~K})=-242 \mathrm{KJ} / \mathrm{mol} \\
\mathrm{CH}_{4}+2 \mathrm{O}_{2} \rightarrow \mathrm{CO}_{2}+2 \mathrm{H}_{2} \mathrm{O} \quad \mathrm{H}^{\circ}(298 \mathrm{~K})=-891 \mathrm{~kJ} / \mathrm{mol}
\end{array}
$$

Several gasification reactors were designed and developed, the most commons are fixed bed (down-draft and up-draft), bubbling fluidized bed (simple, recirculating etc.) [2-5]. According to the design of the reactor to its temperature field, the steps of the gasification could happen in different spots of the gasifier. Several biomass gasification models were tailored with the design, temperature field, particles motion field, kinetic reaction rates [6-11]. Kinetic models require parameters such as reaction rate, residence time, reactor dimensions, superficial velocity, diffusion rate. Thus, the kinetic models provide a wide dimension to investigate the behavior of a gasifier via simulation, they are accurate but computationally intensive and time consuming. Computational fluid dynamics (CFD) play an important role in the modeling of both fluidized-bed gasifier and fixed-bed gasifier. A CFD model implicates a solution of conservation 
of mass, momentum of species, energy flow, hydro-dynamics and turbulence over a defined region. Solutions of such a sophisticated approach can be achieved with commercial software such as ANSYS, Fluent, Phoenics and CFD2000. CFD could appear to be a valid option to explore the various configurations and operating conditions at any scale to identify the optimal configuration depending on the project specification. Anyway, comprehensive CFD simulations for biomass gasification are scarce, mainly due to lack of broad computational resources and the anisotropic nature of biomass [12].

The thermodynamic equilibrium model is a smart tool to calculate the maximum gasification performance that can be attained in a gasifier. The model calculation is independent of gasifier design, it is also said zero dimensional, moreover it is independent of residence times of the reactants and of their hydrodynamics; thence it is extremely helpful for studying the influence of the process parameters, such as temperature, nature of gasifying agent, equivalence ratio, moisture of biomass, etc. The goals of the present work are to study the main thermodynamic effects in biomass gasification by air, varying the equivalence ratio; and the effects of steam/biomass ratio in steam gasification.

\section{METHOD}

Generally, thermodynamic equilibrium models have a stoichiometric or non-stoichiometric approach. The stoichiometric approach requires a definition of chemical species and of the equilibrium constants of gasification reactions [13]. In the non-stoichiometric approach, no reaction mechanisms are involved in the calculation, Gibbs free energy of the system is minimized without specifying any chemical reaction [14]. The two approaches (stoichiometric and nonstoichiometric) are essentially equivalent. In this work the non-stoichiometric approach was applied that occurs by the minimization of the Gibbs free energy of the chemical species involved in the process.

In order to find the equilibrium composition for a given feed to the gasifier at fixed temperature and pressure, the phases chemical reaction equilibrium criterion can be applied that is expressed as:

$$
\left(\mathrm{dG}_{\text {gasifier }}\right)_{\mathrm{T}, \mathrm{P}}=0
$$

The Gibbs free energy is:

$$
n G=\sum n_{i} \Delta G_{f i}^{0}+\sum n_{i} R T \ln P+R T \sum n_{i} \ln y_{i}+R T \sum n_{i} \ln \hat{\phi}_{i}
$$

The minimization of this function occurs under restraints imposed by the atomic mass balances of each elements of the system and by the method of Lagrangianian undetermined multipliers. A system of $\mathrm{n}$ linear equation is obtained in as many unknown (chemical species involved in gasification). An iterative solution method provided by a commercial freeware software gives the composition corresponding to the minimum Gibbs free energy. The chemical species considered for the chemical equilibrium calculation were: $\mathrm{C}_{6} \mathrm{H}_{10} \mathrm{O}_{4}, \mathrm{O}_{2}$, $\mathrm{N}_{2}, \mathrm{H}_{2} \mathrm{O}, \mathrm{C}, \mathrm{H}_{2}, \mathrm{CO}, \mathrm{CO}_{2}, \mathrm{CH}_{4}$. Biomass was simulated by Ethylidene diacetate, because its elemental composition and heating value are remarkably close biomass. Char was simulated by pure carbon.
Even if the authors understand gasification occurs at equivalence ratio in the range $0.2-0.4$, a larger range $0.1-1$, from pyro-gasification up to complete combustion of the biomass, was investigated. Gasification temperature was varied from 750 up to $950{ }^{\circ} \mathrm{C}$, in five temperature steps. Steam gasification was carried out varying the molar ratio steam/biomass from 0 to 9 . In both the sensitivity analyses the dependent variables detected were dry syngas yield, syngas volumetric composition $\left(\mathrm{H}_{2}, \mathrm{CO}, \mathrm{CO}_{2}, \mathrm{CH}_{4}, \mathrm{~N}_{2}\right)$, syngas heating value, char residue, water condensed and the required or freed heat by the process.

\section{RESULTS AND DISCUSSION}

\subsection{Air gasification}

From Figure 1, a clear increase of the gas yield can be observed with increasing the equivalence ratio. At typical equivalence ratio in the gasification range (0.2-0.4), higher gasification temperature gives the higher gas yield. The higher temperature shifts the thermodynamic equilibrium of gasification reactions towards the gas production. The low heating values of the gas decreases with the increase of the equivalence ratio because more organic matter is burnt. At equivalence ratio in the gasification range 0.2-0.4, the higher is gasification temperature the higher is the heating value (Figure 2). The gas composition shows a decreasing trend of the combustible molecules like hydrogen, carbon monoxide and methane with the equivalence ratio, because of the promotion of their combustion reactions (Figure 3, 4 and 5). It is interesting to observe that the higher is the temperature and the lower is the methane content because higher temperature helps the methane steam reforming. Carbon monoxide and carbon dioxide are mainly linked by the endothermic Boudouard equilibrium reaction, that promotes the carbon monoxide formation at higher temperature. In fact, the higher is the temperature the higher is carbon monoxide and the lower is carbon dioxide (Figure 4 and 6). Nitrogen content at equivalence ratio in the range 0.2-0.4 lies in the range 40-55 vol. \% (Figure 7).

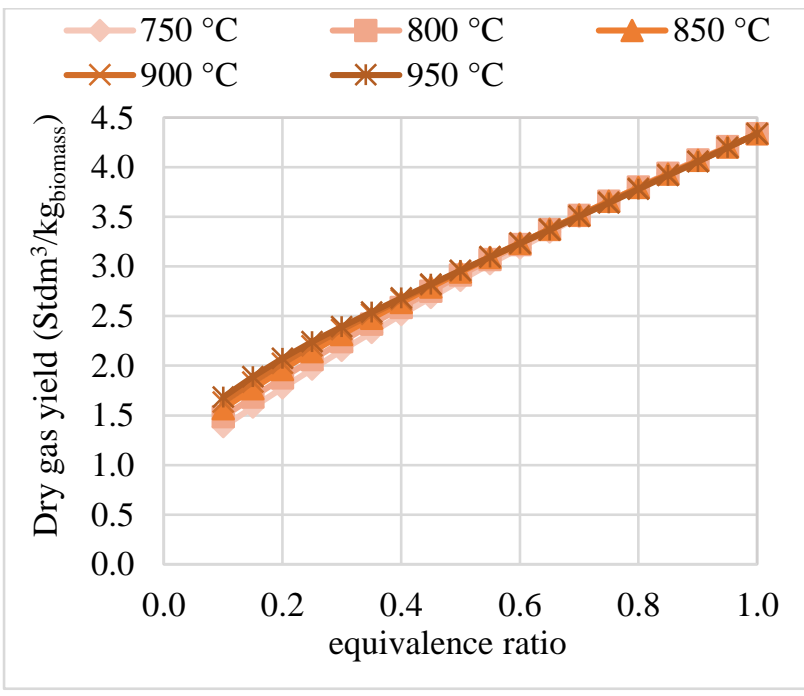

Figure 1. Gas yield vs equivalence ratio 


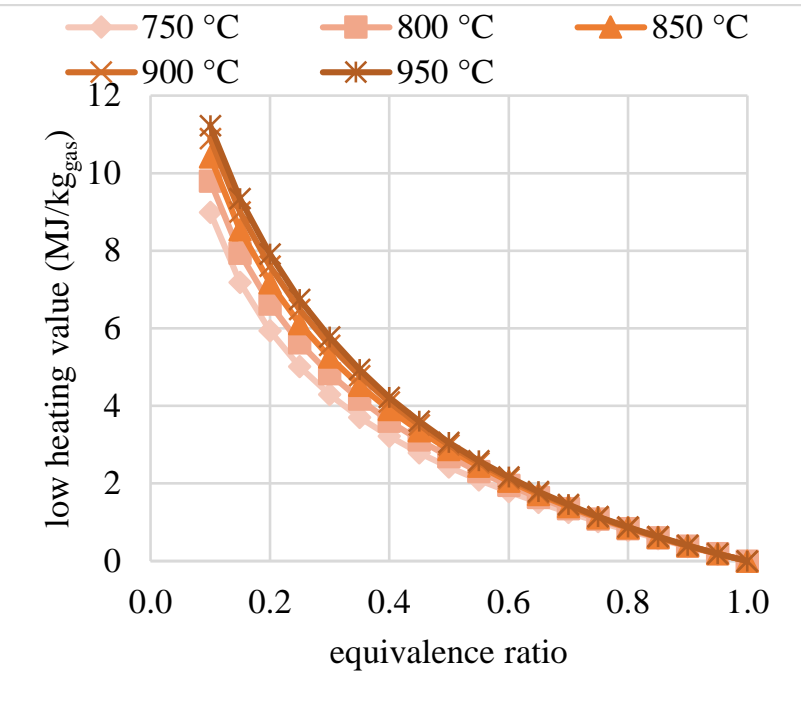

Figure 2. Gas heating value vs equivalence ratio

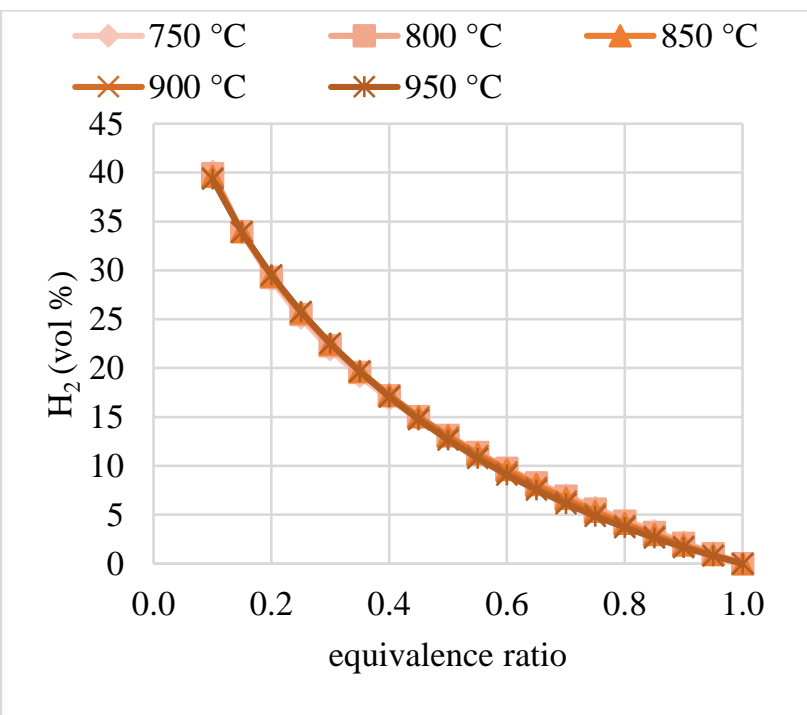

Figure 3. Hydrogen content vs equivalence ratio

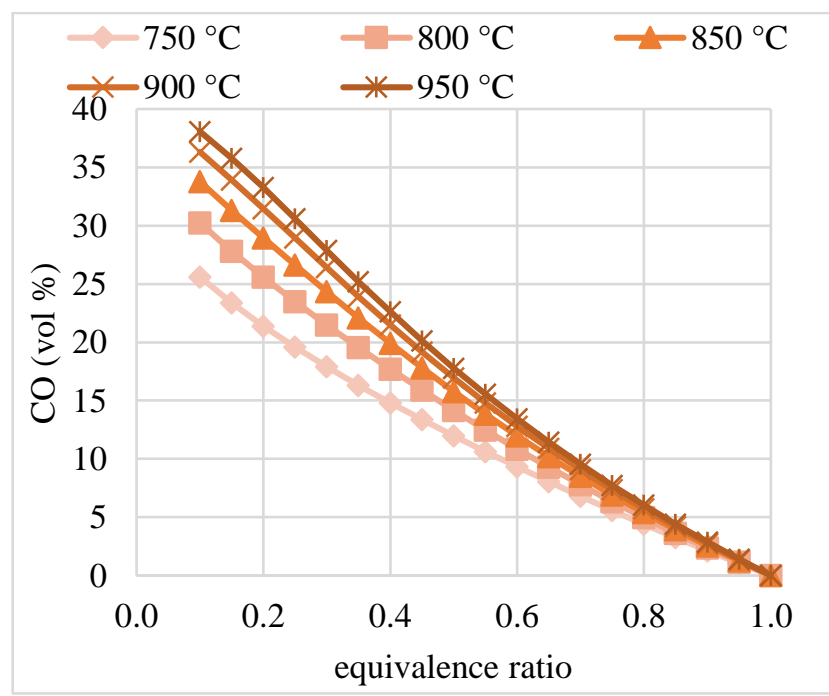

Figure 4. Carbon monoxide content vs equivalence ratio

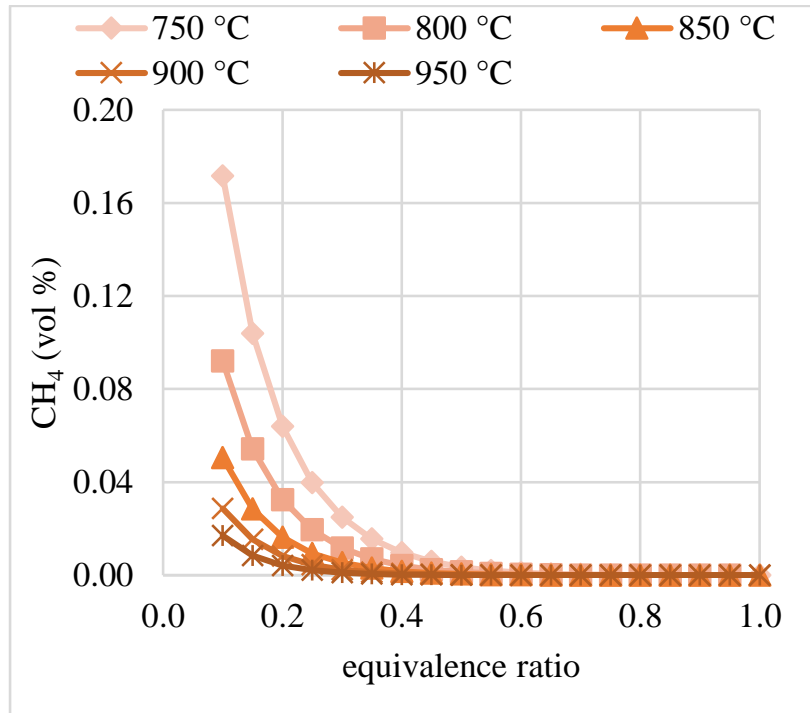

Figure 5. Methane content vs equivalence ratio

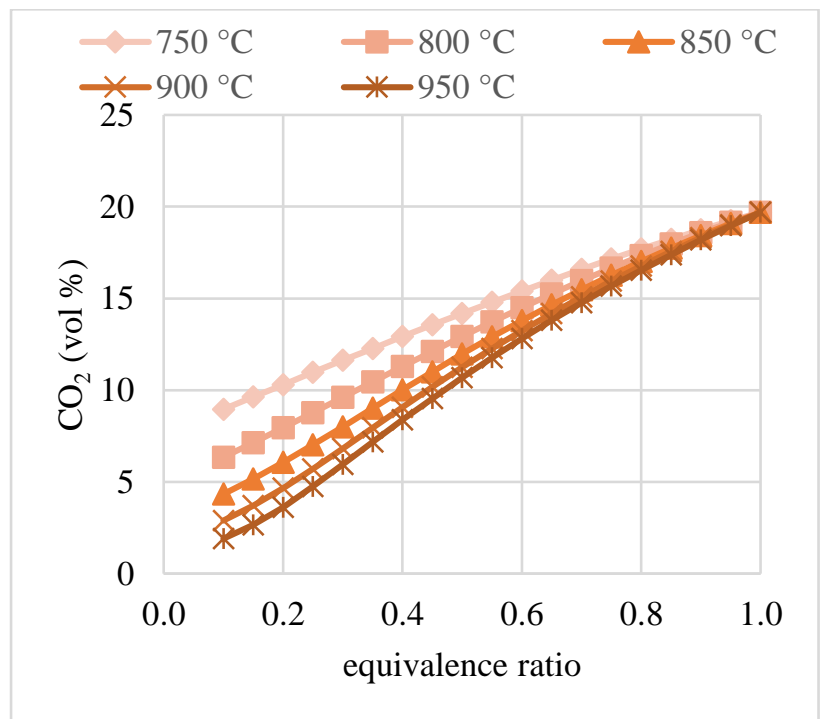

Figure 6. Methane content vs equivalence ratio

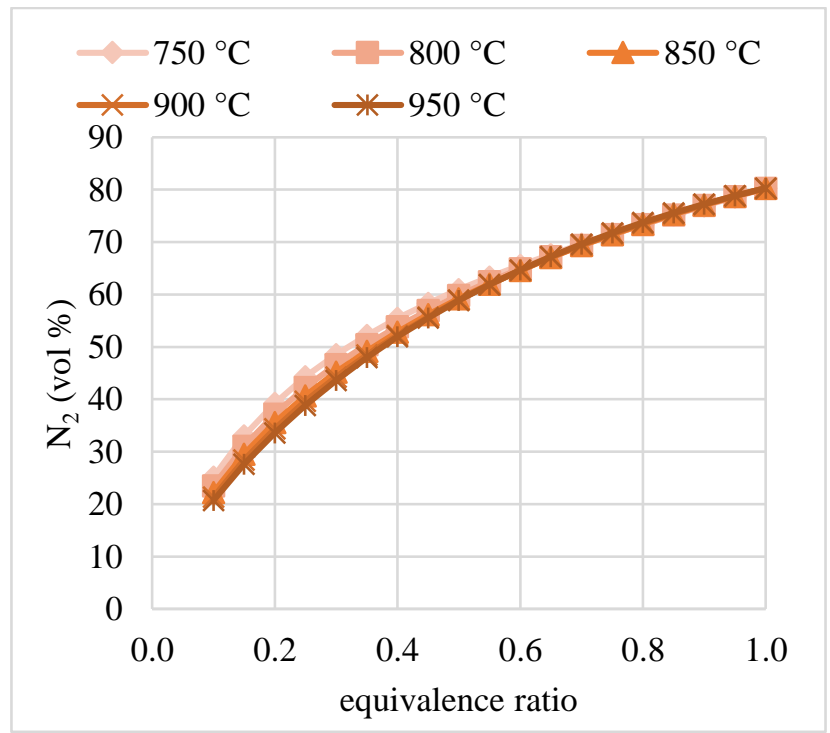

Figure 7. Nitrogen content vs equivalence ratio 
The results of the equilibrium model are in good agreement with experimental data of biomass gasification by air $[15,16]$. The deviation from experimental results was detected with the methane content in the syngas. More in detail the thermodynamic equilibrium model underpredicts it (0.1-0.03 vol. \%) while from experimental results methane content of 56 vol. $\%$ was usually detected.

\subsection{Steam gasification}

In the case of steam gasification, the dry gas yield shows a more smoothed increasing trend with the increasing gasification agent compared to air gasification (Figure 8). This is caused by the less reactivity of the steam compared to the air. As expected, the dry gas yield increases with the temperature. The low heating value of the syngas shows a decreasing trend with the temperature (Figure 9). In the molar steam/biomass ratio range of $2-9$, the heating value lies in the range $18-14 \mathrm{MJ} / \mathrm{kg}$, therefore the syngas can be considered as a fuel gas with medium heating value suitable for combustion in gas turbine in Integrated Gasification Combined Cycles.

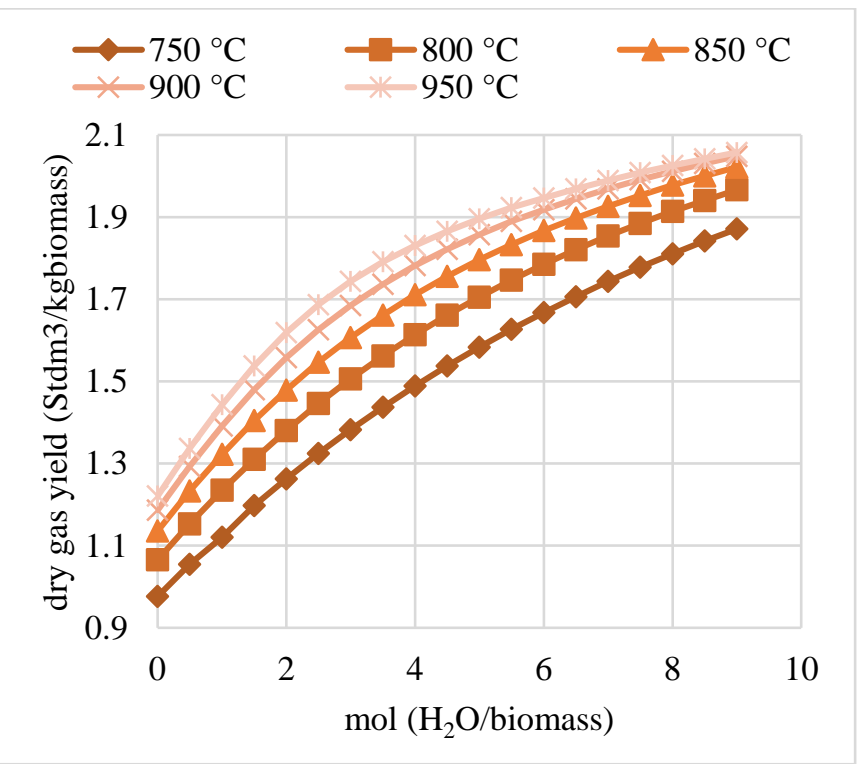

Figure 8. Gas yield vs mol ( $\mathrm{H}_{2} \mathrm{O} /$ biomass $)$

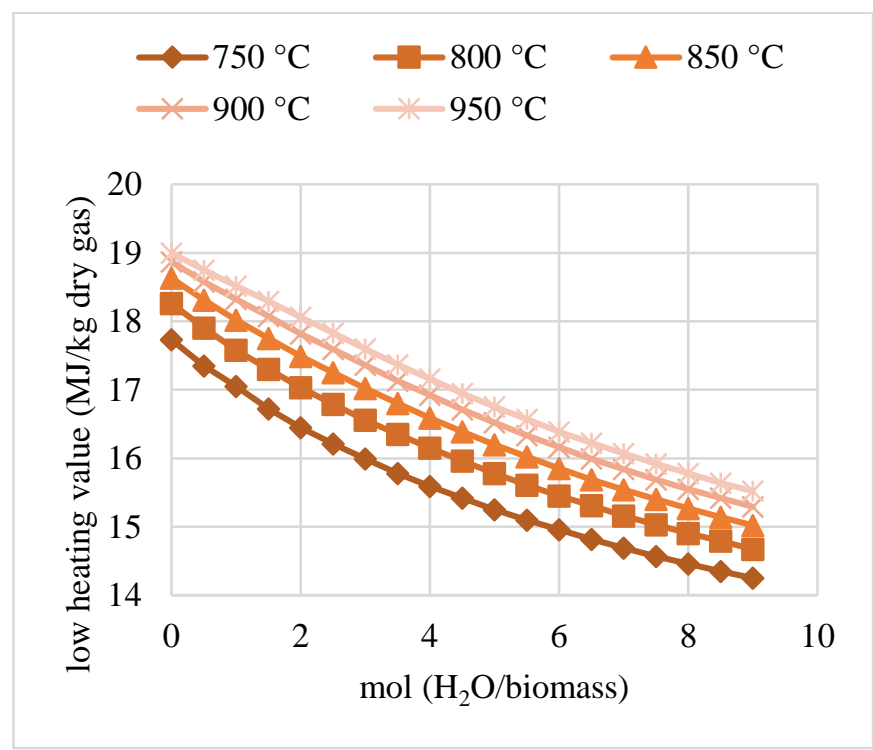

Figure 9. Gas heating value vs $\mathrm{mol}\left(\mathrm{H}_{2} \mathrm{O} /\right.$ biomass $)$

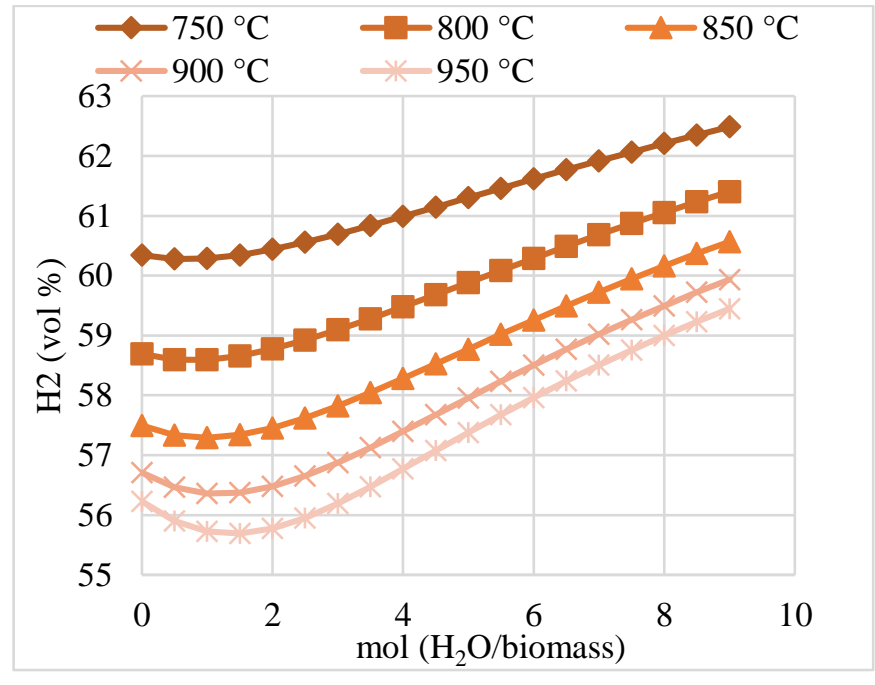

Figure 10. Hydrogen content vs mol $\left(\mathrm{H}_{2} \mathrm{O} /\right.$ biomass $)$

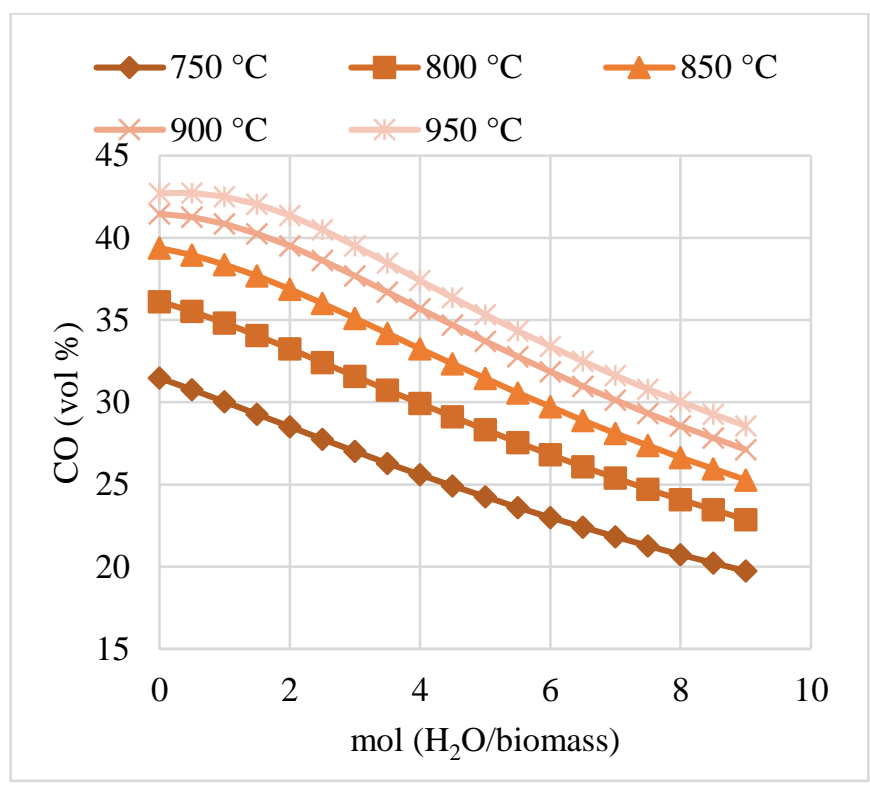

Figure 11. Carbon monoxide content vs mol $\left(\mathrm{H}_{2} \mathrm{O} /\right.$ biomass $)$

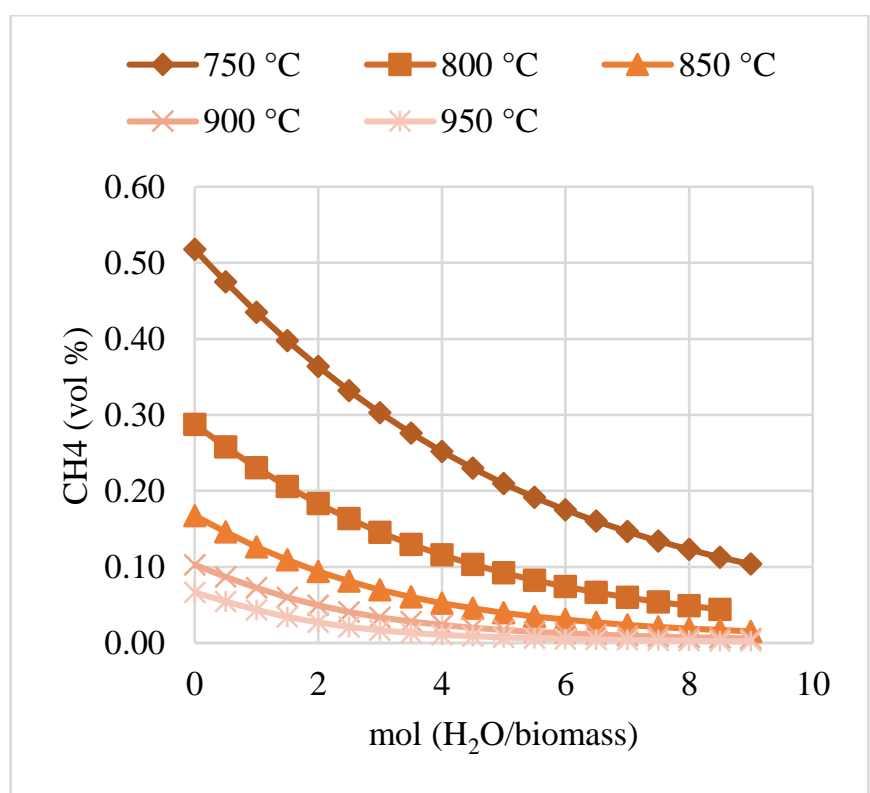

Figure 12. Methane content vs $\mathrm{mol}\left(\mathrm{H}_{2} \mathrm{O} /\right.$ biomass $)$ 


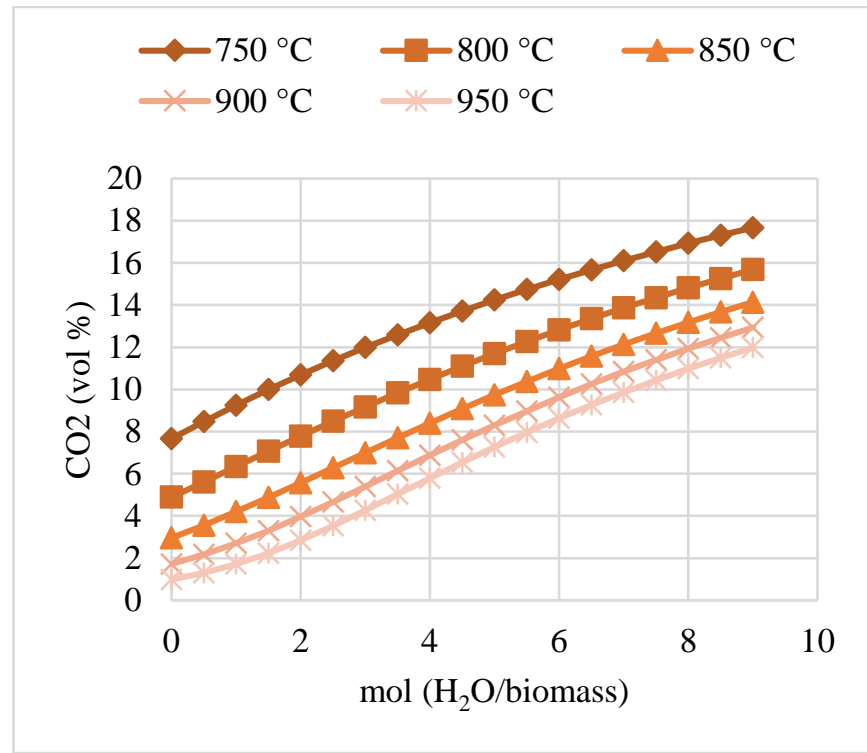

Figure 13. Carbon dioxide content vs mol $\left(\mathrm{H}_{2} \mathrm{O} /\right.$ biomass $)$

The decreasing trend of the dry gas heating value with the steam/biomass ratio can be mainly justified by the water gas shift reaction advancement. In fact, steam injection shifts the carbon monoxide towards the production of hydrogen and permanent inert gas like carbon dioxide. This hypothesis is corroborated by the gas composition with the molar steam/biomass. An increase of carbon dioxide up to 18 vol \% and a global increase of hydrogen up to $62 \mathrm{vol} \%$, with steam/biomass were detected (Figure 10 and 13). Moreover, it is remarkably interesting to observe that the higher hydrogen and carbon dioxide concentration in the syngas occur with the lower temperature because of the exothermicity of the water gas shift reaction. The main feature of steam gasification is the production of a medium heating value syngas with high hydrogen content not achievable with other gasification medium. In fact, biomass is hydrogen deficient feedstock, in order to obtain hydrogen rich gas and the injection of a rich hydrogen gasification medium can cover this bottleneck. From the thermodynamic analysis a syngas with molar $\mathrm{H}_{2} / \mathrm{CO}$ of about 2-3 can be obtained with a molar steam/biomass ratio equal to 9 , according to the gasification temperature. Syngas with these $\mathrm{H}_{2} / \mathrm{CO}$ ratio could be particularly useful for green chemicals synthesis such as methanol, ethanol, DME.

\section{CONCLUSION}

The thermodynamic analysis by a zero-dimensional model is a smart tool to obtain useful information about the influence of the process variables on the gasification process. The high temperature of the process limits the kinetic effects and with good approximation allow to the thermodynamic calculation by minimization of the free Gibbs energy to provide results quite close to a real running gasifier. Deviations compared to real running gasifier stands in the methane content in the produced syngas that is underpredicted by this thermodynamic analysis.

In the case of air gasification with equivalence ratio in the range $0.2-0.4$, a dry gas yield of $1.8-2.7 \mathrm{Stdm} / \mathrm{kg}_{\text {biomass }}$ was observed. The low heating value in the same range of equivalence ratio varied from 7.9 to $3.2 \mathrm{MJ} / \mathrm{kg}$. A decrease of combustible molecule content in the syngas was observed with increasing equivalence ratio. The syngas features comply with its valorization for heat and power production in internal combustion engine working with poor gas.

In the case of steam gasification interesting effects were observed on the syngas composition and heating value. In fact, varying the steam/biomass molar ratio up to 9 , the hydrogen and carbon dioxide content in syngas increased up to 62 and 18 vol. $\%$, while carbon monoxide decreased up to 20 vol. $\%$. A syngas with this composition could fit, after proper upgrading, with the synthesis of green chemical such as methanol, DME, ethanol. From an energetic point of view, a syngas with a medium LHV was detected (18-14 MJ/kg) suitable for combustion in gas turbine in Integrated Gasification Combined Cycles.

\section{REFERENCES}

[1] Chen, Q., Yang, R., Zhao, B., Li, Y., Wang, S., Wu, H., Zhuo, Y.Q., Chen, C. (2014). Investigation of heat of biomass pyrolysis and secondary reactions by simultaneous thermogravimetry and differential scanning calorimetry. Fuel, 134: 467-476. https://doi.org/10.1016/j.fuel.2014.05.092

[2] De Bari, I., Barisano, D., Cardinale, M., Matera, D., Nanna, F., Viggiano, D. (2000). Air gasification of biomass in a downdraft fixed bed: A comparative study of the inorganic and organic products distribution. Energy \& Fuels, 14(4): 889-898. https://doi.org/10.1021/ef990243g

[3] Cerone, N., Zimbardi, F., Contuzzi, L., Alvino, E., Carnevale, M.O., Valerio, V. (2014). Updraft gasification at pilot scale of hydrolytic lignin residue. Energy \& Fuels, 28(6): 3948-3956. https://doi.org/10.1021/ef500782s

[4] Campoy, M., Gómez-Barea, A., Villanueva, A.L., Ollero, P. (2008). Air - steam gasification of biomass in a fluidized bed under simulated autothermal and adiabatic conditions. Industrial \& Engineering Chemistry Research, 47(16): $\quad$ 5957-5965. https://doi.org/10.1021/ie800220t

[5] Barisano, D., Freda, C., Nanna, F., Fanelli, E., Villone, A. (2012). Biomass gasification and in-bed contaminants removal: Performance of iron enriched Olivine and bauxite in a process of steam $/ \mathrm{O}_{2}$ gasification. Bioresource Technology, 118: 187-194. https://doi.org/10.1016/j.biortech.2012.05.011

[6] Califano, F., Mongiello, C., Freda, C. (2017). Combined heat and power production from meat and bone meal via gasification and gas turbine: Technical and economic analysis. Waste and Biomass Valorization, 8(3): 975-986. https://doi.org/10.1007/s12649-016-9628-8

[7] Giltrap, D.L., McKibbin, R., Barnes, G.R.G. (2003). A steady state model of gas-char reactions in a downdraft biomass gasifier. Solar Energy, 74(1): 85-91. https://doi.org/10.1016/S0038-092X(03)00091-4

[8] Wang, Y., Kinoshita, C.M. (1993). Kinetic model of biomass gasification. Solar Energy, 51(1): 19-25. https://doi.org/10.1016/0038-092X(93)90037-O

[9] Rogel, A., Aguillon, J. (2006). The 2D Eulerian approach of entrained flow and temperature in a biomass stratified downdraft gasifier. American Journal of Applied Sciences, 3(10): 2068-2075. 
[10] Sharma, A.K. (2008). Equilibrium modeling of global reduction reactions for a downdraft (biomass) gasifier. Energy Conversion and Management, 49(4): 832-842. https://doi.org/10.1016/j.enconman.2007.06.025

[11] Canneto, G., Freda, C., Braccio, G. (2015). Numerical simulation of gas-solid flow in an interconnected fluidized bed. Thermal Science, 19(1): 317-328. https://doi.org/10.2298/TSCI121220002C

[12] Patra, T.K., Sheth, P.N. (2015). Biomass gasification models for downdraft gasifier: A state-of-the-art review. Renewable and Sustainable Energy Reviews, 50: 583593. https://doi.org/10.1016/j.rser.2015.05.012

[13] Mendiburu, A.Z., Carvalho Jr, J.A., Coronado, C.J. (2014). Thermochemical equilibrium modeling of biomass downdraft gasifier: Stoichiometric models. Energy, 66: 189-201. https://doi.org/10.1016/j.energy.2013.11.022
[14] Mendiburu, A.Z., Carvalho Jr, J.A., Zanzi, R., Coronado, C.R., Silveira, J.L. (2014). Thermochemical equilibrium modeling of a biomass downdraft gasifier: Constrained and unconstrained non-stoichiometric models. Energy, 71: 624-637. https://doi.org/10.1016/j.energy.2014.05.010

[15] Cao, Y., Wang, Y., Riley, J. T., Pan, W. P. (2006). A novel biomass air gasification process for producing tarfree higher heating value fuel gas. Fuel Processing Technology, 87(4): https://doi.org/10.1016/j.fuproc.2005.10.003

[16] Freda, C., Nanna, F., Villone, A., Barisano, D., Brandani, S., Cornacchia, G. (2019). Air gasification of digestate and its co-gasification with residual biomass in a pilot scale rotary kiln. International Journal of Energy and Environmental Engineering, 10(3): 335-346. https://doi.org/10.1007/s40095-019-0310-3 